\title{
Factor Accumulation, Externalities and Absorptive Capacity in Regional Growth: Evidence from Europe
}

\author{
Juan Jung and Enrique López-Bazo
}

Juan Jung. AQR-IREA, Universitat de Barcelona, Av. Diagonal 690, 08034 Barcelona, Spain. Tel: +34616963716. E-mail: juanjung@gmail.com

Enrique López-Bazo. AQR-IREA, Universitat de Barcelona, Av. Diagonal 690, 08034 Barcelona, Spain. Tel: +34934037041. E-mail: elopez@ub.edu

\begin{abstract}
This paper proposes a model which incorporates capital accumulation and spatial spillovers across economies, while allowing for regional differences in absorptive capacity. This model is estimated using a sample of EU regions, over a period including the enlargement of the single-market area in the middle of the first decade of the 21 st century. Results confirm the relevance of local absorptive capacity that is directly linked with the process of making the most of externalities. Capital deepening reduced the role of capital in explaining the regional productivity gap, but was not enough to help lagging regions to equal the return to human capital investments reached by most advanced regions.
\end{abstract}

JEL Codes: C21, O10, R11

Keywords: Regional Disparities, Absorptive Capacity, Technological Interdependence, Spatial Econometrics 


\section{INTRODUCTION}

Over the last decades, literature on growth and development has intended to explain the huge disparities in productivity levels among world economies. This field of study is important, because decoding the sources of disparities will surely provide a useful input which should guide the agenda for research and policy advice. As stated by Caselli (2005), if factors were found to account for most of disparities, then development economics should focus on explaining low rates of factor accumulation. In contrast, if efficiency differences were found to play a large role, the task would consist in explaining why some economies are able to extract more output than others from their inputs. Additionally, following the advances in the literature, adding the role of the local context and that of spillovers into the equation may produce a more global and realistic perspective, in which decoding the interactions among them will surely provide useful information. For instance, if local conditions produce differences in absorptive capacity, then similar policies may produce different results in diverse regions. As an example, in isolated regions with poor local conditions the investment in physical capital may not yield the expected return, because of inadequate local social-filter and its geographical location, which may make them low exposed to spillovers. This must be taken into account when designing policies, as for example the European cohesion programs, which are oriented to regions which have in common the fact that are poorer in comparison with the core, but that may differ in terms of geographical location and local context.

Nelson and Phelps (1966) were among the first to assert the crucial role of absorptive capacity on growth, emphasizing the link between higher education and technological diffusion. Their approach assigned an indirect role for human capital (through its incidence in technology), rather than the more conventional consideration of human 
capital as an additional input of production. In the same line, Cohen and Levinthal (1990) argued that the ability to exploit external knowledge is largely a function of prior related knowledge which depends, among other factors, on the advanced technical training of workers; whereas Benhabib and Spiegel (1994) claimed that the ability of an economy to adopt and implement external technology depends on its human capital stock. Recent empirical evidence has provided support to the role of human capital as a key determinant of absorptive capacity. For example, results on the entrepreneurial activity in the US metropolitan areas in Qian, Acs and Stough (2013) led the authors to conclude that the chief contribution of human capital is on building entrepreneurial absorptive capacity rather than creating knowledge-based entrepreneurial opportunities. On the other hand, technological diffusion soon became linked with geography. For instance, Keller (2002) found that technological spillovers were local, not global, as the benefits from foreign externalities decreased with distance. The idea of spatially bounded spillovers, in addition to the stylized fact of a spatial distribution of wealth and poverty in the world, plus the development of the New Economic Geography literature (see for instance Krugman, 1991) made the spatial dependence patterns almost impossible to ignore in the analysis. In recent years, López-Bazo, Vayá and Artis (2004), Fingleton and López-Bazo (2006), Ertur and Koch (2007), and Koch (2008, 2010) proposed growth models which explicitly accounted for spatial dependence and externalities. Basile, Capello and Caragliu (2012) even claim that other forms of proximity, such as technological, relational and social, reinforce the effects of geographical proximity.

Numerous studies have focused on regional growth disparities in Europe (see for instance Sala-i-Martin, 1996; Quah, 1996; López-Bazo et al., 1999; Magrini, 2004; Bosker, 2009; Koch, 2010). Some of them have also incorporated the spatial dimension 
to their analysis, which was found to play a crucial role (see, among others, Fingleton and López-Bazo, 2006; Basile, 2008). The relevance of the spatial patterns in the distribution of wealth and poverty in Europe revealed in these studies makes that regional analyses of economic growth should take this characteristic into account. This is even more important since the enlargement of the European Union (EU) towards the countries of the Centre and East of Europe (hereafter CEE countries), which has exacerbated the amount of regional disparities. Actually, the enlargement provided a challenge to the EU regional cohesion policy. With the inclusion of 10 countries $^{1}$ in 2004 plus Bulgaria and Romania in 2007, the EU became a 27-country single-market area. As many of these countries had at that time income levels around 40 per cent of the EU average, the enlargement increased inequalities and produced the replacement of the former North/South polarization towards a new North-West/East pattern (Mora, Vayá and Suriñach, 2004; Ertur and Koch, 2006; Marrocu, Paci and Usai, 2013). Existing evidence indicate that dispersion in Gross Domestic Product (GDP) per head had been reduced since late-nineties to 2008 , but despite that, inequalities persist, and have even increased within some CEE countries (European Commission, 2010; Monastiriotis, 2014). In that context, it seems worth to study the sources behind the evolution of regional inequalities in the entire EU in a period including years before and after the enlargement of the mid-2000s.

The openness of CEE economies prompted the inflows of external capital through Foreign Direct Investment (FDI), as stated by Bijsterbosch and Kolasa (2010) and European Commission (2010). For that reason, capital deepening and technological catch-up should not be analyzed in isolation, as capital accumulation through FDI may also act as vehicle for economic restructuring and technological diffusion (Bijsterbosch and Kolasa, 2010). Because of that, the reference model should consider not only 
capital accumulation as an engine of growth, but also additional sources, as for example a learning-by-doing process (Arrow, 1962). Additionally, according to Klenow and Rodriguez-Clare (2005), FDI flows have a relation with geographical distance and, therefore, spatial dependence should be also considered. The incidence of geography can take place through other channels. In this sense, trade-related flow of ideas across countries is believed to be another channel of geography incidence in spillovers (Coe and Helpman, 1995; Koch, 2008; Rodriguez-Pose and Crescenzi, 2008). The strength of these spillovers can be seen, for instance, as related to the intensity of trade between economies. In that sense, geography is again expected to play an important role in the process of technological diffusion. For all those reasons, spatial interactions should be considered as additional sources of spillovers. Finally, these externalities may not always be incorporated automatically by those concerned, as there can be regional differences in absorptive capacity. This may be reflected through a wide range of social and institutional conditions, constituting a social-filter which may include educational achievements, productive employment of human resources, and demographic structure (Rodriguez-Pose and Crescenzi, 2008).

In the light of the reduction of income disparities which took place in period 1999-2007 (European Commission, 2010), the analysis in this paper focuses in decoding its sources (capital intensity and/or technological catch-up), and in the role played by the local context (through absorptive capacity) in the process of making the most of externalities. In this regard, the strategy followed by this paper is twofold. On the one hand, a theoretical model is proposed, consisting in an extension of the framework developed by Ertur and Koch (2007) and Koch $(2008,2010)$, but going a step further, as it allows for differences across regions in local absorptive capacity. In a second step, that model is fitted for a set of EU regions in the period 1999-2008. Finally, the estimate of the 
parameters of the model is used to perform a development accounting exercise, following Easterly and Levine (2001), intending to find how much of the gap between rich and poor EU regions can be attributed to differences in physical capital, and how much can be attributed to technology. In this regard, it should be mentioned that King and Levine (1994) concluded that capital accounted for around half of disparities in a sample of 102 countries, whereas results in Young $(1994,1995)$ suggested that the "miracle" of the eastern Asian countries in the second half of the twentieth century was mainly a case of factor accumulation. In his recent contribution, Koch (2008) showed that incorporating spatial externalities to the analysis made physical capital to increase dramatically its contribution, accounting in some cases for 90 per cent of the development gap among a sample of 91 countries in 1995. He concluded that neglecting spatial interactions might potentially bias the role of physical capital in the development process. His model, however, did not account for differences in local absorptive capacity. It may also be the case that the contribution of factor accumulation and that of technology to disparities across regions differ from those across countries. In contrast, the hypothesis that guides the analysis in this paper is that local absorptive capacity is crucial for explaining the sources of regional disparities in the EU.

The rest of the paper is structured as follows. Section 2 sketches the theoretical model which takes into account externalities across regions and assumes that they differ in their abilities to make the most of these spillovers. Section 3 introduces the data and descriptive analysis, while the estimation of the coefficients of the model and the results of the development decomposition are discussed in section 4. Finally section 5 concludes. 


\section{A MODEL WITH EXTERNALITIES AND ABSORPTIVE CAPACITY}

We build our model on that proposed by Ertur and Koch (2007) and Koch (2008), in which for each regional economy $i$ a Cobb-Douglas production function exhibits constant returns to scale in labour $(L)$ and physical capital $(K)$ :

$$
Y_{i}=A_{i}^{*} K_{i}^{\alpha} L_{i}^{1-\alpha}
$$

The aggregate level of technology in $i, A_{i}^{*}$, depends on some proportion of exogenous technology, common to every region, $\left(\Omega^{*}\right)$, and also on learning-by-doing physical capital externalities and on technological interdependence between economies:

$$
A_{i}^{*}=\Omega^{*} k_{i}^{*\left(\varnothing+\lambda h_{i}\right)} \prod_{j \neq i}^{N} A_{j}^{*\left(\gamma w_{1 i j}+\delta h_{i} w_{2 i j}\right)}
$$

where $k_{i}^{*}$ is defined as physical capital per worker, since as pointed out by Ertur and Koch (2007), knowledge is supposed to be embodied in physical capital per worker and not in levels, in order to avoid scale effects. $h_{i}$ represents endowment of human capital per worker, which intends to measure regional differences in the abilities to adopt and implement technological externalities, whereas $w_{1 i j}$ and $w_{2 i j}$ denote the measures of the amount of interaction between regions $i$ and $j$, that may be similar or different.

The production technology in this paper does not consider thus human capital as a conventional input. Instead, human capital is incorporated as an argument of the aggregate level of technology. There have been some papers which were unable to find a significant impact of human capital as a standard input. ${ }^{2}$ On the other hand, Nelson and Phelps (1966) and Benhabib and Spiegel (1994) found evidence of human capital incidence through technology, as it constitutes an important element to be able to incorporate technological advances generated abroad. In this spirit, our model incorporates human capital as a measure of local absorptive capacity. ${ }^{3}$ It is understood 
that part of the learning-by-doing externalities may have an impact on technology regardless of the level of human capital, because even if workers are not highly embodied with education, they may still learn something in the process (this effect is measured through the parameter $\emptyset \geq 0$ ). At the same time, this learning process will be accelerated the higher the skills of the workers (this is measured through $\lambda \geq 0$ ). In a similar way, absorptive capacity will play a key role in the technological interdependence across economies. As before, it is assumed that some benefit is obtained from interaction regardless of human capital $(\gamma \geq 0)$, but the absorptive capacity will be enhanced with higher levels of skills $(\delta \geq 0)$.

Therefore, in contrast with the specification for the aggregate level of technology in Ertur and Koch (2007) and in Koch (2008), we assume that the effect of externalities from capital accumulation in region $i$ on its level of technology depends positively on the existing stock of human capital in that region. The same applies in the case of technical progress generated elsewhere. Its effect on the level of technology in region $i$ is assumed to depend on its absorptive capacity that, in turn, is determined by the endowment of human capital. The model in the above-mentioned papers imposes a similar rate of absorption in all regions regardless of the endowment of human capital. In such a case, $\lambda=\delta=0$. Instead of imposing such a constraint, in this paper we advocate the existence of differences across regions in the absorptive capacity linked to the availability of human capital in each region.

The interpretation of the parameters in (2) is the key of the model. If $\varnothing=0(\gamma=0)$, then learning-by-doing (technological spatial interdependence) will not take place in the absence of skilled workers. At the same time, $\lambda=0(\delta=0)$ will reflect a negligible role of human capital in enhancing learning-by-doing (interregional technological 
spillovers). On the contrary, if $\lambda>0$ and/or $\delta>0$, regions highly endowed with human capital will have higher capacity for technology adoption. Similarly, poor regions will face difficulties in catching-up with the rich areas unless they are endowed with a certain level of human capital. If learning-by-doing externalities were verified, then a capital deepening process will indirectly produce a technology improvement in the economy, making a two-source growth process (for instance, convergence as a result of capital stock and technological catch-up). Finally, if $\varnothing=\lambda=\gamma=\delta=0$, the specification is the original model proposed by Solow (1956), whereas, as mentioned above, the one in Ertur and Koch (2007) and Koch (2008) results if $\lambda=\delta=0$. In the former case, capital deepening does not have an impact on technological catch-up, while in the latter it takes place but regardless of the availability of skilled labor in each region.

Technological spatial spillovers imply that regions must be analyzed as an interdependent system. In doing so, it is convenient to write down the model in matrix terms for a system with $N$ regions, and to express the variables in (1) in units of labour (output and physical capital in per-worker terms), and log-linearized. Thus, hereafter, $y$, $k, A$, and $\Omega$ denote the vectors with the logarithms of output per worker, capital per worker, aggregate level of technology, and the common-to-all-regions technology. In turn, $h$ denotes a diagonal matrix whose elements are the regional endowment of human capital. Thus, technology in (2) can be re-written in log matrix terms as:

$$
A=\Omega+(\varnothing I+\lambda h) k+\left(\gamma W_{1}+\delta h W_{2}\right) A
$$

where: 
$A=\left(\begin{array}{c}A_{1} \\ A_{2} \\ \vdots \\ A_{N}\end{array}\right) \quad \Omega=\left(\begin{array}{c}\Omega \\ \Omega \\ \vdots \\ \Omega\end{array}\right) h=\left(\begin{array}{cccc}h_{1} & 0 & \ldots & 0 \\ 0 & h_{2} & \ldots & 0 \\ \vdots & \vdots & \ddots & \vdots \\ 0 & 0 & \ldots & h_{N}\end{array}\right)$

and

$$
k=\left(\begin{array}{c}
k_{1} \\
k_{2} \\
\vdots \\
k_{N}
\end{array}\right) W_{s}=\left(\begin{array}{cccc}
0 & w_{S 12} & \ldots & w_{S 1 N} \\
w_{S 21} & 0 & \ldots & w_{s 2 N} \\
\vdots & \vdots & \ddots & \vdots \\
w_{S N 1} & w_{S N 2} & \ldots & 0
\end{array}\right)
$$

and $w_{s i j}$ (for $s=1,2$ ) measures frictions between regions $i \neq j$. The reasoning behind the specification of the elements in $W_{s}$ is that knowledge embodied in one region spills over the others but does so with intensity that diminishes with friction. The more intense is the connection of region $i$ with region $j$, the lower is the friction between the two, and the higher $w_{s i j}$. That is to say, the higher is the potential benefit of region $i$ from spillovers generated in $j$.

Equation (3) can be expressed as:

$A-\left(\gamma W_{1}+\delta h W_{2}\right) A=\Omega+(\varnothing I+\lambda h) k \Rightarrow\left(I-\gamma W_{1}-\delta h W_{2}\right) A=\Omega+(\varnothing I+\lambda h) k$,

which can be rearranged, presuming that $\left(I-\gamma W_{1}-\delta h W_{2}\right)$ is invertible, ${ }^{4}$ as:

$$
A=\left(I-\gamma W_{1}-\delta h W_{2}\right)^{-1} \Omega+\left(I-\gamma W_{1}-\delta h W_{2}\right)^{-1}(\varnothing I+\lambda h) k
$$

As it can be seen in (4), the level of technology is affected by physical capital externalities and by spatial interactions. Also, it shows that a region's ability to absorb and adopt innovations generated elsewhere affects its level of technology: regions with higher endowments of human capital are expected to make more profit from externalities. 
Replacing (4) in the log-linear version of (1) with the variables in units of labor results in:

$$
y=\left(I-\gamma W_{1}-\delta h W_{2}\right)^{-1} \Omega+\left(I-\gamma W_{1}-\delta h W_{2}\right)^{-1}(\varnothing I+\lambda h) k+\alpha k .
$$

Pre-multiplying both sides by $\left(I-\gamma W_{1}-\delta h W_{2}\right)$ :

$$
\left(I-\gamma W_{1}-\delta h W_{2}\right) y=\Omega+(\varnothing I+\lambda h) k+\alpha\left(I-\gamma W_{1}-\delta h W_{2}\right) k
$$

After some rearrangements, this yields:

$$
y=\Omega+(\varnothing+\alpha) k+\lambda h k-\alpha \gamma W_{1} k-\alpha \delta h W_{2} k+\gamma W_{1} y+\delta h W_{2} y .
$$

This expression shows that under the assumption of interregional externalities whose strength is a function of the absorptive capacity of each region, local productivity depends on local physical capital, on the productivity and physical capital of other regions, and also on all these variables in interaction with local human capital. As a result, the change in local productivity induced by capital deepening in a region is affected by externalities within the region and from other regions, and by its endowment of human capital. Interestingly, local productivity is also expected to vary with capital deepening in the other regions as a result of technological diffusion that cross regional borders. Formally speaking, output-physical capital elasticities from (5) are defined as:

$$
\xi_{k} \equiv \frac{\partial y}{\partial k}=\alpha I+\left(I-\gamma W_{1}-\delta h W_{2}\right)^{-1}(\varnothing I+\lambda h)
$$

where $I$ denotes the $N x N$ identity matrix.

$\xi_{k}$ is an $N x N$ matrix with the elasticity of output per worker in each region with respect to its own level of physical capital per worker and with the elasticities with respect to physical capital per worker in all the other regions. These elasticities depend on the capital share in income, on the learning-by-doing process, and on spatial interactions, 
through the spatial multiplier $\left(I-\gamma W_{1}-\delta h W_{2}\right)^{-1}$. Also, from (7) it is clear that elasticities will be higher in those regions endowed with higher levels of human capital, ceteris paribus. All in all, in comparison to the Solow model, the existence of externalities across regions increases the effect of capital on productivity. And with respect to Ertur and Koch (2007) and Koch (2008), differences in absorptive capacity, through the availability of skilled individuals, make some regions more prone to incorporate innovations originated elsewhere and thus to improve their level of technology.

As for the effect of changes in the endowment of human capital on productivity, the corresponding elasticities are defined as:

$$
\begin{gathered}
\xi_{h} \equiv h\left(\frac{\partial y}{\partial h}\right)=h\left(\left(I-\gamma W_{1}-\delta h W_{2}\right)^{-1}\left(\delta W_{2}\right)\left(I-\gamma W_{1}-\delta h W_{2}\right)^{-1} \Omega\right) \\
+\left(I-\gamma W_{1}-\delta h W_{2}\right)^{-1}\left(\delta W_{2}\right)\left(I-\gamma W_{1}-\delta h W_{2}\right)^{-1}(\varnothing I+\lambda h) k \\
+\left(I-\gamma W_{1}-\delta h W_{2}\right)^{-1} \lambda k .
\end{gathered}
$$

$\xi_{h}$ is an $N x 1$ vector whose elements are the elasticities of output per worker in each region with respect to the own level of human capital. These elasticities depend not only on the human capital stock, but also on the physical capital stock and on the spatial interactions, through the spatial multiplier.

Finally, it needs to be mentioned that the inclusion of the mechanism of absorptive capacity modifies the decomposition of the gap in the level of output per worker suggested by Easterly and Levine (2001), and adapted to the case of the existence of spillovers across economies by Koch (2008). Defining $\kappa$ as the $\log$ of the capital-output ratio, and $y^{*}, \kappa^{*}$, and $h^{*}$ as $y, \kappa$ and $h$ in relative terms with respect to a reference region, equation (5) can be expressed as: 


$$
y^{*}=\left(I-\gamma W_{1}-\delta h^{*} W_{2}\right)^{-1} \Omega+\left(\alpha I+\left(I-\gamma W_{1}-\delta h^{*} W_{2}\right)^{-1}\left(\varnothing I+\lambda h^{*}\right)\right)\left(\kappa^{*}+y^{*}\right)
$$

Defining a diagonal matrix $D$ whose elements are the output per worker in each region in relative terms with respect to the reference region, and pre-multiplying both sides of the previous equation by the inverse of $D$ results in:

$$
\begin{aligned}
D^{-1} y^{*}=D^{-1} & \left(I-\gamma W_{1}-\delta h^{*} W_{2}\right)^{-1} \Omega \\
& +\left(\alpha D^{-1}+D^{-1}\left(I-\gamma W_{1}-\delta h^{*} W_{2}\right)^{-1}\left(\varnothing I+\lambda h^{*}\right)\right) \kappa^{*} \\
& +\alpha 1+\left(D^{-1}\left(I-\gamma W_{1}-\delta h^{*} W_{2}\right)^{-1}\left(\varnothing I+\lambda h^{*}\right)\right) y^{*}
\end{aligned}
$$

where $\alpha 1$ is a column vector with all elements equal to $\alpha$. After some arrangements, the contribution of capital to the gap in the level of development is obtained as:

$$
\begin{aligned}
\Upsilon_{k}=\alpha 1 & +\left(\alpha D^{-1}+D^{-1}\left(I-\gamma W_{1}-\delta h^{*} W_{2}\right)^{-1}\left(\varnothing I+\lambda h^{*}\right)\right) \kappa^{*} \\
& +\left(D^{-1}\left(I-\gamma W_{1}-\delta h^{*} W_{2}\right)^{-1}\left(\varnothing I+\lambda h^{*}\right)\right) y^{*}
\end{aligned}
$$

As in Koch (2008), the contribution of physical capital depends on three terms: the capital share in income, the capital-output ratio, and finally the spatial distribution of productivity. However, in the second and third terms in (9), the region's ability to adopt technology enhances the influence of capital, as it strengths the externalities.

In order to easier comparisons, the percentage gap in output for each region $i$ relative to a reference region $r$ is calculated:

$$
G A P_{i}=100 \times \frac{(Y / L)_{i}-(Y / L)_{r}}{(Y / L)_{r}}
$$

Then, for a given region $i$, the contribution of capital to accounting for disparities with respect to the reference region is $\Upsilon_{k i} \times G A P_{i}$. 


\section{DATA AND DESCRIPTIVE ANALYSIS}

Our empirical exercise aims at providing evidence on the effect of spatial spillovers and differences in absorptive capacity in the level of productivity of the EU regions. To estimate the coefficients in equation (6) we used data on Gross Value Added (GVA) per worker and on the physical capital stock per worker for all sectors (both measured in constant 2000 Euros), from the Cambridge Econometrics database. As for the absorptive capacity, it was proxied by a measure of human capital. In particular, following the previous literature which indicates that high skills are a requisite to assimilate new technology (e.g. Leiponen, 2005; Manca, 2012; Qian, Acs and Stough, 2013) we opted for using data on the percentage of workers with tertiary-level education over the whole workforce. The source of the data for this variable is the Eurostat Regio database. However, the lack of available data for the share of high skilled workers imposed some constraints in terms of the sample of regions included in the analysis as well as for the time period under consideration. Among the first 15-entry countries, regional data on the share of workers with tertiary education is not available for Denmark, Sweden, and Luxembourg. In turn, such information is only available for 4 of the CEE countries that acceded the EU in 2004: the Czech Republic, Hungary, Poland, and Slovakia. Finally, no regional data on educational attainment is available yet for a long-enough period for Bulgaria and Romania, the two countries that joined the EU in 2007. Still, the lack of data for some regions before 1999 forced us to define the period under analysis from this year to 2008 that is the last year covered by the Regio database when this study was carried out.

All in all, the sample included 215 NUTS2 regions from 16 EU countries for the period between 1999 and 2008 (the complete list of regions is detailed in the appendix). Some simple summary statistics of the variables under analysis are provided in Table 1 for the 
beginning and the end of the period under analysis, whereas Figures 1 and 2 plot the corresponding estimates of the density functions, as a way of summarizing the characteristics of the entire regional distribution of these variables. As already reported by the previous literature, our descriptive results confirm the existence of sizeable disparities in labor productivity that persist over the period under analysis. The gap, in log terms, between the most and less productive regions in the sample (Inner London and Podkarpackie) was 2.36 in 1999, similar to that observed in 2008 between Inner London and Lubelskie (the region with the lowest level of productivity that year), which was 2.30. Interestingly, the gap in capital per worker was of a similar order of magnitude: 2.27 between Oberbayern and Podkarpackie in 1999, and 2.31 between Flevoland and Lubelskie in 2008..$^{5}$ The comparison of the measure of absorptive capacity also reveals marked regional differences, with Inner London as the region that made the most intensive use of high skilled labor all over the period.

The estimated density functions in Figures 1 and 2 reveal that disparities went beyond those for the regions with the highest and lowest values for the variables under analysis. The one corresponding to labor productivity reveals a bimodal distribution, with an important amount of regions near the core, and a less numerous but distant group at the left, which constitutes a periphery (mainly of CEE regions). The distance between the two modes is rather high and remained stable over the period under analysis. In turn, the density of capital per worker has a long left tail but without a clear mode in that area, which indicates larger dispersion for values below the average than in the case of productivity. In fact, the comparison of the densities for the two variables suggests that polarization in the distribution of productivity was not just caused by the distribution of the capital-labor ratio. In agreement with our hypothesis in this paper, differences in the level of technology and in the absorption capacity might well have played a role. The 
density for the measure of absorptive capacity, the share of workers highly endowed with human capital, provides preliminary support to this hypothesis, since it reveals a substantial mass of probability at the left of the distribution, corresponding to regions with much lower endowments of human capital. It is worthwhile noting that the increase in the endowment of education in the entire EU over the period under analysis caused a shift to the right in the distribution which, in any case, did not prevent the presence of strong regional disparities in the share of workers with tertiary education in 2008 .

As an additional element of the simple descriptive analysis in this section, we want to mention that the distribution of the variables under analysis is characterized by a clear geographical or spatial pattern. The representation in maps of labor productivity, capital per worker, and the measure of human capital (not included here to save space but available from the authors) provides the well-known core-periphery pattern commonly reported for the EU. Broadly speaking, the lowest levels of productivity, physical capital, and human capital are found in the south and CEE regions, while the highest levels are seen in the traditional core. This brings about a distribution of the variables that is characterized by strong spatial dependence. Using the Moran's I and Geary's C statistics to measure the strength of the spatial association, and a square-distance inverse weight matrix (row-normalized) ${ }^{6}$, the figures in Table 2 clearly confirm positive spatial correlation for all variables for 1999 and 2008.

\section{RESULTS}

This section discusses the results obtained when estimating the coefficients of the model described in section 2 for the set of EU regions over the period 1999 to 2008 . Firstly, we 
comment the results regarding the estimate of the coefficients for each year. Then, the estimated coefficients are used to compute the physical and human capital elasticities as defined in equations (7) and (8). These elasticities are calculated for each region and then used to compute averages for the groups of Core, Southern, and CEE regions. Finally, estimates are used for a development accounting exercise in which the contribution of capital, distinguishing by the components defined in equation (9), is assessed. Again, average results for the Core, South, and CEE regions are computed and compared over the period under analysis.

Equation (6) is used to estimate the coefficients of the growth model with technological externalities that depend on the economy absorptive capacity. Since this model includes spatial lags of both endogenous and exogenous variables, Ordinary Least Squares do not provide consistent estimates of the coefficients. Instead a Maximum Likelihood estimator, which ensures the desired properties, is applied. Also, we account for the fact that the empirical specification in (6) includes non-linear restrictions in the coefficients (see the appendix for details of the estimation procedure). ${ }^{7}$

Estimation of equation (6) involves some other issues that are worth discussing. Firstly, as stated by LeSage and Pace (2009), $W_{1}$ and $h W_{2}$ are required to be not functionally related. That technical limitation prevents using the same weights matrix for $W_{1}$ and $W_{2}$. As a result, it will be supposed that for spatial externalities that do not rely on local absorptive capacity, interaction will take place with its closest neighbours. For that reason, $W_{1}$ will be represented by a first-order contiguity matrix. For technological externalities whose absorption in each region depends on local human capital levels, it will be assumed that interactions have a higher spatial scope, taking place among regions within a radius of 250 kilometers. This distance is consistent with the evidence in, for instance, Moreno, Paci and Usai (2005) and Rodriguez-Pose and Crescenzi 
(2008) for the scope of technological externalities in Europe. ${ }^{8}$ Therefore, $W_{2}$ will be represented by a $250 \mathrm{~km}$ cut-off distance matrix. Matrices $W_{1}$ and $W_{2}$ may still share some overlapping information, but this is not believed to be a problem, as $W_{2}$ is premultiplied by $h$, and the resulting matrix $h W_{2}$ appears to be sufficiently differentiated with respect to $W_{1}$ to avoid identification problems. ${ }^{9}$

Another important issue in the estimation of the empirical model in equation (6) is the normalization procedure for the referred matrices, considering the required stability condition, $\left|I-\gamma W_{1}-\delta h W_{2}\right|>0$. In cases of two-weight matrices affecting the endogenous variable, a common approach is to row-normalize each matrix (Lacombe, 2004; LeSage and Pace, 2009). However, this is not desirable in the case of the specification in this paper because to row-normalize $h W_{2}$ means to get rid of the term $h$, as the same values multiply every element of each row. A solution in this case is to follow Beck, Gleditsch and Beardsley (2006), and to joint-normalize both matrices, so that the rows of both matrices, $w_{1 i}$ and $h_{i} w_{2 i}$, sum to one. ${ }^{10}$

The estimation results are summarized in Table 3, for years 1999, 2002, 2005 and 2008. ${ }^{11}$ Before discussing results of the estimated coefficients it should be said that the specification seems to account fully for the spatial dependence in productivity. Although Lagrange multiplier tests to detect remaining spatial dependence cannot be applied in this case due to the model non-linearity, a Moran's I test was applied to the residuals of each regression, with results suggesting no further spatial dependence in any case.

A first look at the results confirms a high value for $\alpha$, averaging 0.78 for the four years of analysis. This is higher than the typical capital share in income in national accounts, usually one-third (as found by Koch, 2010), but closer to Koch (2008) results of 0.46- 
0.52 for a Spatial Durbin Model, and $0.68-0.70$ for a Spatial Error Model (although Koch works with a different sample, consisting of 91 countries). Another important confirmation is the presence of both kinds of externalities affecting the TFP: learningby-doing and spatial interaction. The pattern is clear as regards the first type of external effects: $\varnothing$ is never significant, while $\lambda$ is significant at 1 per cent in all years excepting 1999. This means that human capital seems to have a direct role in the absorption of spillovers from capital accumulation. This may explain why in Koch's results the parameter $\emptyset$ is not significant as in the absence of interaction with local conditions these externalities do not seem to have an incidence on technological levels. ${ }^{12}$ This result suggests that the presence of a high skilled workforce enhances the return to physical capital investment. This means that two economies which have made a similar investment in physical capital may have a different return depending on its human capital endowment. Significance of $\lambda$ implies a higher return for physical capital investment for those regions with highest skilled workforce, suggesting that both types of capital are complementary. This may have some important consequences for regional development, as regions with poor human capital endowment (especially from the periphery) will have little technological benefit from capital accumulation spillovers and as a result will face difficulties to catch-up. As stated before, some peripheral regions received important amount of FDI during the period. It can be supposed that these capital flows were mostly endowed with advanced technology (in contrast to local stocks), and in the light of these results, possibly only the relatively good human capital-endowed regions have been able to make the most of that advances.

With respect to the effect of technology generated beyond the borders of the region, that is to say of spatial spillovers in technology, the estimates of the corresponding coefficients $(\gamma$ and $\delta)$ are significant at 1 per cent in all years $(\delta$ at 1.04 per cent in 
2008). The coefficient of the direct measure of technological absorption, $\gamma$, averages stable values of 0.9 , while that of the measure which incorporates absorptive capacity through human capital, $\delta$, decreases over the period from 0.75 in 1999 to 0.48 in $2008 .{ }^{13}$ However, this trend should not be seen as a declining in the role of local abilities, because average levels of human capital increased during the period. Combining the estimated value of the coefficient with the average share of tertiary education in the workforce results in only a slight decrease over the period ( 0.15 in 1999 versus 0.13 in 2008). In any case, the estimates confirm that the absorption of technology generated beyond the borders of the region was enhanced by local capabilities, which results in differences in the absorptive capacity. In other words, although all regions benefited from technical progress generated elsewhere, those EU regions with high endowments of skilled workers made the most of it. This result thus qualifies the recent evidence reported in Vogel (2015) for a sample of EU 15 regions, which assigns a negligible effect of human capital on region's absorptive capacity.

All in all, these results confirm that studies aiming at estimating the effect of physical capital accumulation on regional disparities in productivity, and the contribution corresponding to technology diffusion, should account for differences across regions in the absorptive capacity as a consequence of differences across regions in the endowment of human capital. Next, the estimates in Table 3 are used to compute the capital-productivity elasticities and to perform a development accounting analysis for the EU regions in the period under analysis.

\section{Physical and Human Capital Elasticities}

The calculation of physical and human capital elasticities, through respectively equations (7) and (8), is an effective way to consider the amount of dispersion in returns 
across regions. They indicate that the return on investments in one of these types of capital in a region is conditional on its endowment of the other, which may constitute a limitation to overcome for lagging regions. It is, therefore, important to analyze how local conditions and geographic location can have an impact on the return to investments in physical and human capital. The elasticities were calculated for each region in the sample, and their distributions summarized by the corresponding density functions, estimated by the kernel method. They are represented in Figures 3 and 4 (see also the maps provided in Figures A1 to A3 in the appendix) for the first and last years under analysis.

As to physical capital, it is important to note that Equation (7) gives an indication of the elasticity after an increase in physical capital in a specific region (the diagonal elements of the resulting matrix), but also that corresponding to an increase in physical capital in other regions. Therefore, the overall elasticity of an increase in physical capital in all regions can be computed. Figure 3 shows the densities of the elasticity of physical capital, distinguishing between local (left panel) and overall elasticity (right panel). The former is the one for investments in the region, while the latter reflects the productivity response in the region to physical capital investments in all regions. It is observed that in both cases the distribution at the end of the period (dashed line) is at the left of that in 1999 (continuous line), which means that both local and overall elasticities decreased moderately over the period. Due to the existence of positive spatial externalities, the overall effect of physical capital investments is somewhat higher than the local effect in both years. It is also interesting to note that the local elasticity distribution was more concentrated in 1999 than in 2008, despite the long right tail in the first year analysed, while the opposite applies in the case of the overall elasticity distribution. When the effect of spatial externalities in the accumulation of physical capital is taken into 
account, what is observed is a substantial shrinkage in the distribution between 1999 and 2008. In any case, comparing the distribution of local and overall elasticities for the last year under analysis allows us to conclude that spatial interactions led to an increase in the effect of physical capital investments while, at the same time, contributed to homogenize this effect across regions. This is true except for a group of regions in which the overall elasticity is well above that of most EU regions (mass of probability at around 0.9 and beyond).

In turn, the densities of the human capital elasticity distributions are shown in Figure 4. As indicated in section 2, the role of human capital in our model is constrained to facilitate absorption of technology, generated in the region or elsewhere. Therefore, the return of investments in this type of capital is thought not to spill over other regions. Accordingly, there is not an overall elasticity in the case of human capital, but just the local effect. On the other hand, it should be kept in mind that, as equation (8) indicates, the elasticity of human capital depends on the regional endowment of both types of capital. As a result, disparities across regions in physical capital endowments shapes the regional distribution of returns to investments in human capital. It is observed that the density for 2008 is to the right of that for 1999, which means that, in general, the elasticity of human capital increased over the period analyzed. In fact, inspection of the density for 1999 reveals that the elasticity of human capital was negative in a large number of EU regions at the eve of the new century. In contrast, the density for 2008 suggests that such worrisome negative effect disappeared in the course of the last decade. Investments in human capital had a positive effect on productivity in all EU regions at the end of the period. This was mostly caused by a process of physical capital deepening in regions that departed from rather low values. Still, the density for 2008 reveals a non-negligible mass of probability at the left of the mode (low values of the 
elasticity) and also at the opposite edge of the distribution (values for the elasticity in the range 0.5 to 1$).{ }^{14}$

Next, we discuss the average value of the elasticities in three groups of EU regions: those in the Core of the EU, in the South, and in CEE. ${ }^{15}$ Physical capital elasticities reported in Table 4 show that the CEE regions reach similar levels of elasticity than the Core and South groups. Another interesting fact is that in 1999 there were overall increasing returns to physical capital for all groups of regions, although that was later reversed and in 2008 results were in the order of $0.90-0.93$, which can still be considered as high levels. This suggests that externalities help to counteract to some extent the effect of decreasing returns to physical capital accumulation in the EU regions.

Regarding the effect of human capital, results in Table 4 show that the highest elasticities are estimated for the regions in the Core, followed by Southern and CEE regions respectively. As stated before, the low levels of the human capital elasticity for peripheral regions (especially CEE regions in which negative values for the elasticity are estimated) seem to be explained by their low endowment of physical capital per worker. In the case of the Southern regions, geographic distance to the Core may also constitute a limitation for having lower returns to human capital investment vis-à-vis the most developed regions in the core of the EU.

An interesting pattern derived from the results in Table 4 is the increasing trend of the elasticity of human capital in the period under analysis, which is more pronounced in the South and, especially, in CEE regions. In the latter group, the large negative elasticity at the beginning of the period analyzed may well reflect that these economies were still in the early stages of the transition from communism. They lacked the 
capability for obtaining a return from the human capital of their populations due to the insufficient and obsolete endowment of physical capital, the inadequate system of incentives at the time, and the still low level of ties with economies of Western Europe. In the following years, after the accession to the EU and the openness process that led to important FDI inflows, the increase and modernization of the physical capital endowment along with a more suitable institutional framework, favored that these regions were able to start extracting positive returns to human capital investments at the end of the last decade. This is consistent with a rapid process of skilled biased technical change in these economies, as they experienced a fast shift in technology that favored skilled labor by increasing its relative productivity. This interpretation goes in the same direction as the conclusions reached in some other studies, as for example Esposito and Stehrer (2009), who found evidence of this process in Hungary and Poland between 1995 and 2003. ${ }^{16}$ In a lesser degree, southern regions may still have undergone through a similar process, reaching higher returns to human capital while its development increased through the years.

\section{Development Decomposition}

As mentioned in section 2, the inclusion of the mechanism of absorptive capacity that depends on the stock of skilled workers in each region modifies the decomposition of the gap in the level of output per worker, suggested by Easterly and Levine (2001) and adapted to the case of spillovers across economies by Koch (2008). As a final exercise in this paper, we use the estimate of the coefficients discussed above to implement the decomposition in equation (9). In brief, the goal is to find out how much of the gap between the least and most productive regions in the EU can be attributed to differences in physical capital endowments once the effect associated to regional differences in absorptive capacity is taken into account. 
Firstly, we summarize results by the average of the deciles of the regional productivity distribution, where that for the most productive decile were taken as the benchmark or reference region $-r$ in equation (10). In addition, we also discuss the result of the decomposition for the three groups of EU regions described above, using also the top decile as benchmark. For the sake of saving space, we only report the results for the first and final year of the period analyzed. Those for the other years are available from the authors upon request.

Average results by deciles shown in Figure 5 suggest that for the less productive regions (first three deciles), an important amount of the gap with respect to the highest decile is explained by the contribution of physical capital. The detailed decomposition provides additional insights on the sources of this contribution. It is observed that most of it is due to the return to physical capital $(\alpha)$, whereas the contribution of differences in the capital-output ratio $\left(\kappa^{*}\right)$ is negative. This result is explained by the lesser physical capital requirements of high value-added activities that are more abundant in the most productive EU regions. The capital-output ratio is lower for highly productive activities in the industrial and service sectors located in core economies. In contrast, a relatively high capital-output ratio is observed in mature industrial activities in some of the less productive regions in the EU. ${ }^{17}$ On the other hand, it is observed that the unequal spatial distribution of productivity $\left(y^{*}\right)$ also adds to the contribution of physical capital in the lowest deciles, particularly in 1999.

Results in Figure 5 also reveal that there was a part of the gap not attributable to physical capital, and thus corresponding to technology, at the beginning of the period analyzed. However, this seems to be important only in the case of the less productive regions (first three deciles). Interestingly, the amount of the gap explained by physical capital slightly reduced in 2008 in comparison with 1999 in these regions. In other 
words, there is an increasing portion of the gap for the less productive regions that cannot be explained by physical capital over the period analyzed. This may be the result of a process of capital intensity as a consequence of the deepening in economic integration following the accession to the EU in lagging regions. Correspondingly, it can be deduced an increasing role of technology in explaining productivity differentials between the most and less productive regions in Europe. This phenomenon is also clearly observed for regions with levels of productivity at the median and upper part of the distribution. While almost all the gap was explained by physical capital in 1999 , the contribution of technology is similar or even greater to that corresponding to physical capital in the deciles at the right of the distribution in 2008. That is to say that technology is responsible of a big deal of the differences between regions with middle and middle-upper levels of productivity, and those at the top of the ranking in the most recent years. In this regard, it is important to remember that the contribution of technology is affected by the absorptive capacity which, in turn, depends on the endowment of human capital in each region.

As a final stage of our analysis, Figure 6 summarizes the contribution of physical capital and technology to the gap between the average region in each of the three groups defined above and that of the top decile. As expected, the widest gap is clearly observed for CEE regions, followed by the Southern and Core groups. This is consistent with the fact that most CEE regions are in the first deciles (Figure 5). In fact, results in Figure 6 allow us to state that the features discussed above with respect to these deciles correspond mostly to CEE regions. For instance, it is observed that the negative contribution of differences in the capital-output ratio in 1999 was more intense in the CEE regions than in the Southern group. It can also be observed that the reduction in the contribution of this component over the period was more intense in the CEE than in the 
Southern group. As in the analysis by deciles, the portion of the gap attributable to the return to capital $(\alpha)$ appears to be very important in the three groups of regions, while the contribution of $y^{*}$ is lower and decreasing between 1999 and 2008. As for the gap not explained by physical capital, results for the CEE group point to an increase in the contribution of differences in technology. However, the rise in the portion of the gap attributable to technology over the period is even more important for the Southern and Core regions in the EU. It can be observed how this component was almost negligible for both groups in 1999, whereas it accounted for about one third of the gap observed in 2008 for the Southern group and a bit less than one half for the Core.

To sum up, the decomposition of the regional productivity gap in the EU based on the empirical specification that includes spillovers from physical capital accumulation and diffusion of technology across regions, both shaped by absorption capacity in each region which, in turn, depends on the human capital endowment, reveals that most of the gap is attributable to differences in physical capital. However, a clear trend is observed towards an increasing role of technological differentials. This is so for the less developed regions in the CEE and the South, and also for those in the Core. According with the main hypothesis in this paper, this feature is explained by the role played by human capital as a fundamental factor for the absorption of technology.

\section{CONCLUSIONS}

This paper has proposed a theoretical model that combines technological externalities and differences across regional economies in local absorptive capacity. Its main assumption is that externalities have a crucial role in regional development, although not all regions can make the most of them, as their real impact on productivity is by 
local absorptive capacity, which in turn depends on the human capital endowment of the region. We have shown that the consideration of externalities across regions and local absorptive capacity affects the elasticity of both physical and human capital. Interestingly, the development decomposition derived from such a model has revealed that, in addition to externalities, the local absorptive capacity also plays a substantive role to the contribution of differences in physical capital endowments.

The key coefficients of the model, capturing the effect of externalities and absorptive capacity, have been estimated from the empirical specification derived from the model for a sample of 215 European NUTS2 regions for years in the period from 1999 to 2008. A Maximum Likelihood estimator has been developed to account for its particular spatial characteristics. Results have confirmed the important role of local absorptive capacity, as well as the relevance of externalities in explaining cross-regional differences in productivity. Evidence from European regions indicates that physical capital contributes to explain productivity disparities, not only through the capital share in the economy, but also through the capital-output ratio and externalities. As a result, we can conclude that physical capital has a bigger role than that attributed in some previous studies, although this does not prevent the existence of far from negligible regional efficiency differentials, which also contributed to the productivity gap.

Results for specific groups of regions in the EU have revealed that, despite the recent process of capital deepening and economic integration in CEE economies, regions from this area need to be better endowed with physical capital to be able to reach higher returns to the investments they make in human capital, and to be able to achieve some significant technological catch-up. Regardless of that particular scenario for the CEE regional economies, an increase of factor endowment in the periphery may contribute to 
reduce disparities, though this process is expected to be hindered by geography, since peripheral regions benefit only marginally from spillovers generated in the core.

Some policy implications are derived from the results in this paper. In first place, peripheral regions in Europe seem to have different necessities, depending on their geographic location and the endowment of physical and human capital. As a result, EU policies to stimulate development in lagging regions should be designed taking into account the specific circumstances of each region. On the one hand, the ex-ante policy assessment should consider the particular location of the region, and the real chance of benefiting from spillovers generated elsewhere. It should also take into account that the effects of the stimulus of investments in a lagging region may spillover to other regions. In this context, coordinated actions in groups of regions (instead of individual efforts) may help to counteract the poverty trap generated by geographical location. On the other hand, regional development policies should continue stimulating investments in human capital in the less developed areas. However, for these policies to be effective and human capital investments to have a positive return, a simultaneous deepening in physical capital accumulation is required. Modernization of economic structures and improvements in the institutional framework that favor attraction of investments in physical capital are thus crucial. 


\section{Footnotes}

${ }^{1}$ The 2004 enlargement process included Cyprus, Czech Republic, Estonia, Hungary, Latvia, Lithuania, Malta, Poland, Slovakia and Slovenia.

2 Benhabib and Spiegel (1994) estimated several growth accounting regressions considering human capital as a conventional input, which was found to enter insignificantly, and almost always with a negative coefficient.

3 From a complementary perspective, Cohen and Levinthal (1990) and subsequent studies have provided arguments for the critical role of absorptive capacity at the firm level. This strand of the literature has also pointed to human capital as a key determinant of firm's absorptive capacity (e.g. Qian, Acs and Stough, 2013). We thank an anonymous referee for suggesting this remark.

${ }^{4}$ In second order spatial lag polynomials, invertibility depends on the parameters, $\gamma$ and $\delta$, the two matrices, $W_{l}$ and $h W_{2}$ in our case, and the relationship between $W_{l}$ and $h W_{2}$, which complicates the identification of the feasible range for the spatial parameters (e.g. Beck, Gleditsch and Beardsley, 2006; Lee and Liu, 2010; Badinger and Egger, 2011; Elhorst, Lacombe and Piras, 2012). In this section, we assume that the conditions for the invertibility of $\left(I-\gamma W_{1}-\delta h W_{2}\right)$ are fulfilled. This issue will be further discussed in section 4 for the particular definition of the matrices used in the empirical exercise.

${ }^{5}$ Due to its particular industrial mix, specialized in highly productive services that do not make intensive use of physical capital, Inner London was not the region with the highest capital-labor ratio despite being that with the highest level of labour productivity.

6 Similar results were reached in all cases using first-order contiguity and 250 kilometers cut-off weight matrices (not shown here to save space).

${ }^{7}$ The specification may be extended to a panel data setting, therefore controlling for unobserved regional heterogeneity (see Lee and $\mathrm{Yu}, 2010$ ). However, in addition to the obvious complications caused by the non-linearity of the specification, it should be noticed that pooling the data for the period under study would have hampered the analysis since the matrix $h W_{2}$ evolves with the endowment of human capital and the spatial parameters, $\gamma$ and $\delta$, are likely to vary over time. For that reason, the estimates of the coefficients in this section exploit only the information in the cross-section dimension, although we admit that it would be interesting to explore the effect of unobserved regional heterogeneity in future analyses. We thank an anonymous referee for rising this point.

8 Rodriguez-Pose and Crescenzi (2008) suggest a threshold of a 3-hour drive for innovation spillovers.

${ }^{9}$ We analyzed in detail the two spatial matrices used in the study, particularly with respect to the issue of overlapping information. In this respect, it should be said that the number of links (non-zero elements) in $W_{2}$ is 12.15 percent of all possible interactions, whereas this figure is only 4.04 percent in the case of $W_{l}$. Similarly, the mean number of links is much higher for the distance-based matrix, 13, than for the contiguity matrix, 4.32. Overall, comparison of the two matrices suggests that they actually include different information on potential spatial interactions among the set of EU regions under study. To check the robustness of the results, the inverse combination for $W_{1}$ and $W_{2}$ 
was also tested, but reported lower likelihood. The detailed results are available upon request.

${ }^{10}$ It should be noticed that, in this case, the feasible parameter space is not simply given by values satisfying $|\gamma|+|\delta|<1$, as $W_{1}$ and $h W_{2}$ are not, independently, rownormalised. Instead, the more general condition $|\gamma|+|\delta|<\left(\max \left\{\left\|W_{1}\right\|,\left\|h W_{2}\right\|\right\}\right)^{-1}$ applies (see Lee and Liu, 2010 for further details).

${ }^{11}$ Results for each year in the period under analysis are not included to save space, but they are available upon request. In any case, estimates for the years not reported are similar to those in Table 3 for the closest periods.

${ }^{12}$ Koch (2010) found $\varnothing$ to be not significant in European regions, while Koch (2008) estimated six regressions for 91 countries, varying weight matrices and depreciation rates, and only in one case $\varnothing$ was significant, at a 10 percent level (p-value of 0.094).

${ }^{13}$ These values ensure stability as the required condition of $\left|I-\gamma W_{1}-\delta h W_{2}\right|>0$ is verified.

${ }^{14}$ In order to check for the effect of the inclusion of human capital as a determinant of the region's absorptive capacity, elasticities were computed from the model that does not consider the interaction between $h$ and $W_{2}$, but only $W_{2}$ in the last term of the RHS of equation (3), using the corresponding estimates of the coefficients. In all cases, the distribution of the elasticities computed from the model that accounts for the region's absorptive capacity differs clearly from the one that is obtained when that specific role of human capital is neglected. These results are available upon request.

15 Core: regions from Belgium, Germany, France, Netherlands, Austria, Finland, Ireland, United Kingdom; South: regions from Greece, Spain, Italy and Portugal; CEE: regions from Czech Republic, Hungary, Poland and Slovakia. It is worth to notice that these macro-areas are defined based on a geographical criterion and, to some extent (the northern part of Italy would be the only exception), on well-known differences in the level of economic development and the timing of accession into the European Union. As indicated by an anonymous referee, an alternative would have been to use a spatial clustering algorithm, as the one suggesting by Duque, Anselin and Rey (2012). In our view, this interesting option does not fit into the particular aim of this study, although it might be considered in further analyses of the estimated elasticities.

16 This process happened previously in developed countries. In particular, Berman, Bound and Machin (1998) found evidence of skilled-biased technical change for OECD countries after 1979.

${ }^{17}$ For instance, in 2008, the average capital-output ratio for first decile regions was 4.9, in contrast to an average of 3.7 for the highest decile. 


\section{REFERENCES}

Anselin, Luc. 1988. Spatial Econometrics: Methods and Models. Dordrecht: Kluwer Academic Publishers.

Arrow, Kenneth. 1962. "The Economic Implications of Learning by Doing," Review of Economic Studies, 29(3), 155-173.

Badinger, Harald and Peter Egger. 2011. "Estimation of Higher-order Spatial Autoregressive Cross-section Models with Heteroscedastic Disturbances," Papers in Regional Science, 90(1), 213-235.

Basile, Roberto. 2008. "Regional Economic Growth in Europe: A Semiparametric Spatial Dependence Approach," Papers in Regional Science, 87(4), 527-544.

Basile, Roberto, Roberta Capello and Andrea Caragliu. 2012. "Technological Interdependence and Regional Growth in Europe: Proximity and Synergy in Knowledge Spillovers," Papers in Regional Science, 91(4), 697-722.

Beck, Nathaniel, Kristian Skrede Gleditsch and Kyle Beardsley. 2006. "Space is More than Geography: Using Spatial Econometrics in the Study of Political Economy," International Studies Quarterly, 50(1), 27-44.

Benhabib, Jess and Mark Spiegel. 1994. "The Role of Human Capital in Economic Development. Evidence from Aggregate Cross-country Data," Journal of Monetary Economics, 34(2), 143-173.

Berman, Eli, John Bound and Stephen Machin. 1998. "Implications of Skill-Biased Technological Change: International Evidence," Quarterly Journal of Economics, 113(4), $1245-1280$.

Bijsterbosch, Martin and Marcin Kolasa. 2010. "FDI and Productivity Convergence in Central and Eastern Europe: An Industry-level Investigation," Review of World Economics, 145(4), $689-712$.

Bosker, Maarten. 2009. "The Spatial Evolution of Regional GDP Disparities in the 'Old' and the 'New' Europe," Papers in Regional Science, 88(1), 3-27. 
Caselli, Francesco. 2005. "Accounting for Cross-country Income Differences," in P. Aghion and S. Durlauf (eds.), Handbook of Economic Growth. Vol. 1, Part A. North-Holland: Elsevier, pp. 679-741.

Coe, David and Elhanan Helpman. 1995. "International R\&D Spillovers," European Economic Review, 39(5), 859-897.

Cohen, Wesley and Daniel Levinthal. 1990. "Absorptive Capacity: A New Perspective on Learning and Innovation," Administrative Science Quarterly, 35(1), 128-152.

Duque, Juan, Luc Anselin and Sergio Rey. 2012. "The Max-P-Regions Problem," Journal of Regional Science, 52(3), 397-419.

Easterly, William and Ross Levine. 2001. "It's Not Factor Accumulation: Stylized Facts and Growth Models," The World Bank Economic Review, 15(2), 177-219.

Elhorst, Paul, Donald Lacombe and Gianfranco Piras. 2012. "On Model Specification and Parameter Space Definitions in Higher Order Spatial Econometric Models," Regional Science and Urban Economics, 42(1-2), 211-220.

Ertur, Cem and Wilfried Koch. 2006. "Regional Disparities in the European Union and the Enlargement Process: An Exploratory Spatial Data Analysis, 1995-2000," The Annals of Regional Science, 40(4), 723-765.

Ertur, Cem and Wilfried Koch. 2007. "Growth, Technological Interdependence and Spatial Externalities: Theory and Evidence," Journal of Applied Econometrics, 22(6), 1033-1062.

Esposito, Piero. and Robert Stehrer. 2009. "The Sector Bias of Skill-biased Technical Change and the Rising Skill Premium in Transition Economies," Empirica, 36(3), 351-364.

European Commission. 2010. Investing in Europe's Future. Fifth Report on Economic, Social and Territorial Cohesion. Luxembourg: European Commission, Directorate-General for Regional Policy.

Fingleton, Bernard and Enrique López-Bazo. 2006. "Empirical Growth Models with Spatial Effects," Papers in Regional Science, 85(2), 177-198.

Keller, Wolfgang. 2002. "Geographic Localization of International Technology Diffusion," American Economic Review, 92(1), 120-142. 
King, Robert and Ross Levine. 1994. "Capital Fundamentalism, Economic Development and Economic Growth," Carnegie-Rochester Conference Series on Public Policy, 40, 259-292.

Klenow, Peter and Andres Rodriguez-Clare. 2005. "Externalities and Growth," in P. Aghion and S. Durlauf (eds.), Handbook of Economic Growth. Vol. 1, Part A. North-Holland: Elsevier, pp. 679-741.

Koch, Wilfried. 2008. "Development Accounting with Spatial Effects," Spatial Economic Analysis, 3(3), 321-342.

Koch, Wilfried. 2010. "Growth and Spatial Dependence in Europe,” in A. Páez, J. Gallo, R. Buliung, and S. Dall'erba (eds.), Progress in Spatial Analysis, Methods and Applications, Berlin: Springer, pp. 465-482.

Krugman, Paul. 1991. "Increasing Returns and Economic Geography," The Journal of Political Economy, 99(3), 483-499.

Lacombe, Donald. 2004. "Does Econometric Methodology Matter? An Analysis of Public Policy Using Spatial Econometric Techniques,” Geographical Analysis, 36(2), 105-118.

Lee, Lung-Fei. 2004. “Asymptotic Distributions of Quasi-Maximum Likelihood Estimators for Spatial Autoregressive Models," Econometrica, 72(6), 1899-1925.

Lee, Lung-Fei and Xiaodong Liu. 2010. "Efficient GMM estimation of High Order Spatial Autoregressive Models with Autoregressive Disturbances," Econometric Theory, 26(1), $187-230$

Lee, Lung-Fei and Jihai Yu. 2010. "Estimation of Spatial Autorregressive Panel Data Models with Fixed Effects," Journal of Econometrics, 154(2), 165-185.

Leiponen, Aija. 2005. "Skills and Innovation," International Journal of Industrial Organization, 23(5-6), 303-323.

LeSage, James and R. Kelley Pace. 2009. Introduction to Spatial Econometrics. Boca Ratón: Chapman and Hall/CRC.

López-Bazo, Enrique, Esther Vayá, Toni Mora and Jordi Suriñach. 1999. "Regional Economic Dynamics and Convergence in the European Union," Annals of Regional Science, 33(3), $343-370$ 
López-Bazo, Enrique, Esther Vayá and Manuel Artís. 2004. "Regional Externalities and Growth: Evidence From European Regions," Journal of Regional Science, 44(1), 43-73.

Magrini, Stefano. 2004. "Regional (Di)Convergence," in J. V. Henderson and J. F. Thisse (eds.), Handbook of Regional and Urban Economics. Vol. 4. North-Holland:Elsevier, pp. $2741-2796$.

Manca, Fabio. 2012. "Human Capital Composition and Economic Growth at the Regional Level," Regional Studies 46(10), 1367-1388.

Marrocu, Emanuela, Raffaele Paci and Stefano Usai. 2013. "Productivity Growth in the Old and New Europe: The Role of Agglomeration Externalities," Journal of Regional Science, 53(3), $418-442$

Monastiriotis, Vassilis. 2014. "Regional Growth and National Development: Transition in Central and Eastern Europe and the Regional Kuznets Curve in the East and the West," Spatial Economic Analysis, 9(2), 142-161.

Mora, Toni, Esther Vayá, and Jordi Suriñach. 2004. "The Enlargement of the European Union and the Spatial Distribution of Economic Activity," Eastern European Economics, 42(5), 635.

Moreno, Rosina, Raffaele Paci and Stefano Usai. 2005. "Spatial Spillovers and Innovation Activity in European Regions,” Environment and Planning, 37(10), 1793-1812.

Nelson, Richard and Edmund Phelps. 1966. "Investment in Humans, Technological Diffusion, and Economic Growth,” American Economic Review, 56(1-2), 69-75.

Qian, Haifeng, Zoltan Acs and Roger Stough. 2013. "Regional Systems of Entrepreneurship: the Nexus of Human Capital, Knowledge and New Firm Formation," Journal of Economic Geography, 13(4), 559-587.

Quah, Danny. 1996. "Regional Convergence Clusters across Europe," European Economic Review, 40(3-5), 951-958.

Rodriguez-Pose, Andres and Riccardo Crescenzi. 2008. "Research and Development, Spillovers, Innovation Systems, and the Genesis of Regional Growth in Europe," Regional Studies, 42(1), 51-67. 
Sala-i-Martin, Xavier. 1996. "Regional Cohesion: Evidence and Theories of Regional Growth and Convergence," European Economic Review, 40(6), 1325-1352.

Solow, Robert. 1956. "A Contribution to the Theory of Economic Growth," Quarterly Journal of Economics, 70(1), 65-94.

Vayá, Esther, Enrique López-Bazo, Rosina Moreno, and Jordi Suriñach. 2004. "Growth and Externalities Across Economies: An Empirical Analysis Using Spatial Econometrics," in L. Anselin, R.J.G.M. Florax, and S.J. Rey (eds.), Advances in Spatial Econometrics, Methodology, Tools and Applications. Berlin: Springer, pp. 433-455.

Vogel, Johanna. 2015. "The Two Faces of R\&D and Human Capital: Evidence from Western European Regions," Papers in Regional Science, 94(3), 525-551.

Young, Alwyn. 1994. "Lessons from the East Asian NICs: A Contrarian View," European Economic Review, 38(3-4), 964-973.

Young, Alwyn. 1995. "The Tyranny of Numbers: Confronting the Statistical Realities of the East Asian Growth Experience," Quarterly Journal of Economics, 110(3), 641-680. 


\section{APPENDIX}

\section{Sample of Regions}

Belgium: Région de Bruxelles-Capitale / Brussels HoofdstedelijkGewest; Prov. Antwerpen; Prov. Limburg (BE); Prov. Oost-Vlaanderen; Prov. Vlaams-Brabant; Prov. WestVlaanderen; Prov. Brabant Wallon; Prov. Hainaut; Prov. Liège; Prov. Luxembourg (BE); Prov. Namur.

Czech Republic: Praha; StredníCechy; Jihozápad; Severozápad; Severovýchod; Jihovýchod; Strední Morava; Moravskoslezsko.

Germany: Stuttgart; Karlsruhe; Freiburg; Tübingen; Oberbayern; Niederbayern; Oberpfalz; Oberfranken; Mittelfranken; Unterfranken; Schwaben; Berlin; Bremen; Hamburg; Darmstadt; Gieben; Kassel; Mecklenburg-Vorpommern; Braunschweig; Hannover; Lüneburg; Weser-Ems; Düsseldorf; Köln; Münster; Detmold; Arnsberg; Saarland; Schleswig-Holstein; Thüringen.

Ireland: Border; Midland and Western; Southern and Eastern.

Greece: AnatolikiMakedonia, Thraki; KentrikiMakedonia; DytikiMakedonia; Thessalia; Ipeiros; Ionia Nisia; DytikiEllada; StereaEllada; Peloponnisos; Attiki; VoreioAigaio; NotioAigaio; Kriti.

Spain: Galicia; Principado de Asturias; Cantabria; País Vasco; Comunidad Foral de Navarra; La Rioja; Aragón; Comunidad de Madrid; Castilla y León; Castilla-la Mancha; Extremadura; Cataluña; Comunidad Valenciana; Illes Balears; Andalucía; Región de Murcia; Canarias (ES).

France: Île de France; Champagne-Ardenne; Picardie; Haute-Normandie; Centre (FR); BasseNormandie; Bourgogne; Nord - Pas-de-Calais; Lorraine; Alsace; Franche-Comté; Pays de la 
Loire; Bretagne; Poitou-Charentes; Aquitaine; Midi-Pyrénées; Limousin; Rhône-Alpes; Auvergne; Languedoc-Roussillon; Provence-Alpes-Côte d'Azur; Corse.

Italy: Piemonte; Valle d'Aosta/Vallée d'Aoste; Liguria; Lombardia; Provincia Autonoma Bolzano/Bozen; Provincia Autonoma Trento; Veneto; Friuli-Venezia Giulia; EmiliaRomagna; Toscana; Umbria; Marche; Lazio; Abruzzo; Molise; Campania; Puglia; Basilicata; Calabria; Sicilia; Sardegna.

Hungary: Közép-Magyarország; Közép-Dunántúl; Nyugat-Dunántúl; Dél-Dunántúl; ÉszakMagyarország; Észak-Alföld; Dél-Alföld.

Netherlands: Groningen; Friesland (NL); Drenthe; Overijssel; Gelderland; Flevoland; Utrecht; Noord-Holland; Zuid-Holland; Zeeland; Noord-Brabant; Limburg (NL).

Austria: Burgenland (AT); Niederösterreich; Wien; Kärnten; Steiermark; Oberösterreich; Salzburg; Tirol; Vorarlberg.

Poland: Lódzkie; Mazowieckie; Malopolskie; Slaskie; Lubelskie; Podkarpackie; Swietokrzyskie; Podlaskie; Wielkopolskie; Zachodniopomorskie; Lubuskie; Dolnoslaskie; Opolskie; Kujawsko-Pomorskie; Warminsko-Mazurskie; Pomorskie.

Portugal: Norte; Algarve; Centro (PT); Lisboa; Alentejo.

Slovakia: Bratislavský kraj; Západné Slovensko; Stredné Slovensko; Východné Slovensko.

Finland: Itä-Suomi; Etelä-Suomi; Länsi-Suomi; Pohjois-Suomi; Aland.

United Kingdom: Tees Valley and Durham; Northumberland and Tyne and Wear; Cumbria; Cheshire; Greater Manchester; Lancashire; Merseyside; East Yorkshire and Northern Lincolnshire; North Yorkshire; South Yorkshire; West Yorkshire; Derbyshire and Nottinghamshire; Leicestershire, Rutland and Northamptonshire; Lincolnshire; Herefordshire, Worcestershire and Warwickshire; Shropshire and Staffordshire; West Midlands; East Anglia; Bedfordshire and Hertfordshire; Essex; Inner London; Outer 
London; Berkshire, Buckinghamshire and Oxfordshire; Surrey, East and West Sussex; Hampshire and Isle of Wight; Kent; Gloucestershire, Wiltshire and Bristol/Bath area; Dorset and Somerset; Cornwall and Isles of Scilly; Devon; West Wales and The Valleys; East Wales; Northern Ireland (UK).

\section{Empirical specification and estimation procedure}

It can be assumed that for every region, the exogenous component of the TFP can be decomposed into a constant term, and a region-specific shock. As a result, (6) can be expressed as:

$$
y=\mu+(\varnothing+\alpha) k+\lambda h k-\alpha \gamma W_{1} k-\alpha \delta h W_{2} k+\gamma W_{1} y+\delta h W_{2} y+\varepsilon,
$$

where $\varepsilon$ constitutes the $N x l$ vector of perturbations. The model to be estimated resembles the spatial-Durbin model, as it includes spatial lags of both endogenous and exogenous variables. For that reason, Ordinary Least Squares (OLS) estimations will not be consistent. An alternative method is Maximum Likelihood, which under the compliance of some conditions ensures the desirable properties of consistency, efficiency and asymptotic normality (Anselin, 1988). According to Lee (2004), the quasi-maximum likelihood estimators of the Spatial Autoregressive Model can also be considered if disturbances are not truly normally distributed.

As the empirical equation involves non-linear restrictions, the estimation procedure must take them into account. For that reason, the estimation process will be similar to the proposed by Vayá et al. (2004). With some rearrangement, the empirical equation can also be expressed as:

$$
\left(I-\gamma W_{1}-\delta h W_{2}\right) y=\mu+(\varnothing+\alpha) k+\lambda h k-\alpha\left(\gamma W_{1}+\delta h W_{2}\right) k+\varepsilon
$$

For different combination of values of $\gamma \geq 0$ and $\delta \geq 0$, the Nx4 matrix of pseudo-regressors $X_{0}$ is computed: 


$$
X_{0}=\left(\begin{array}{ccccc}
1 & k_{1} & h_{1} k_{1} & \gamma \sum_{j=1}^{N} w_{11 j} k_{j}+\delta h_{1} \sum_{j=1}^{N} w_{21 j} k_{j} \\
\vdots & \vdots & \vdots & \vdots \\
1 & k_{N} & h_{N} k_{N} & \gamma \sum_{j=1}^{N} w_{1 N j} k_{j}+\delta h_{N} \sum_{j=1}^{N} w_{2 N j} k_{j}
\end{array}\right)
$$

This transformation to four pseudo-regressors allows the incorporation of the nonlinear constraints. As a result, the logarithm of the likelihood function is:

$$
\begin{gathered}
\ln L=\ln \left|I-\gamma W_{1}-\delta h W_{2}\right|-\frac{N}{2} \ln \sigma^{2} \\
-\frac{1}{2 \sigma^{2}}\left[\left(I-\gamma W_{1}-\delta h W_{2}\right) y-X_{0} \beta\right]^{\prime}\left[\left(I-\gamma W_{1}-\delta h W_{2}\right) y-X_{0} \beta\right],
\end{gathered}
$$

where $\beta$ is a vector of parameters. Then, OLS is applied to the following equations: (i) $X_{0}$ on $y$, (ii) $X_{0}$ on $W_{1} y$, and (iii) $X_{0}$ on $h W_{2} y$, obtaining the $4 \mathrm{x} 1$ parameters vectors $\beta_{0}, \beta_{L 1}, \beta_{L 2}$. From those regressions the following residuals are obtained: $e_{0}, e_{L 1}$ and $e_{L 2}$. With those residuals, the logarithm of the concentrated likelihood function can be expressed as:

$$
\ln L_{C}=C+\ln \left|I-\gamma W_{1}-\delta h W_{2}\right|-\frac{N}{2} \ln \left\langle\frac{\left(e_{0}-\gamma e_{L 1}-\delta e_{L 2}\right)^{\prime}\left(e_{0}-\gamma e_{L 1}-\delta e_{L 2}\right)}{N}\right\rangle .
$$

where $C$ is a constant. This process is performed for each combination of $\gamma$ and $\delta$. These parameters $\gamma$ and $\delta$ are chosen in order to maximize the concentrated likelihood function. Then, the remaining parameters are obtained following the next expression:

$$
\beta_{M L}=\beta_{0}-\gamma \beta_{L 1}-\delta \beta_{L 2}
$$

$\beta_{M L}$ represents a $4 \times 1$ vector of parameters. With those estimations, the structural parameters $(\mu, \emptyset, \lambda, \alpha)$ can be easily recovered and all restrictions are fulfilled. Asymptotic variances for the estimated parameters are obtained by computing the inverse of the information matrix. The variance of the implied parameter $\emptyset$ is computed through the delta method. 
Maps of estimated elasticities 
FIGURE A1: Distribution of the local elasticity of physical capital
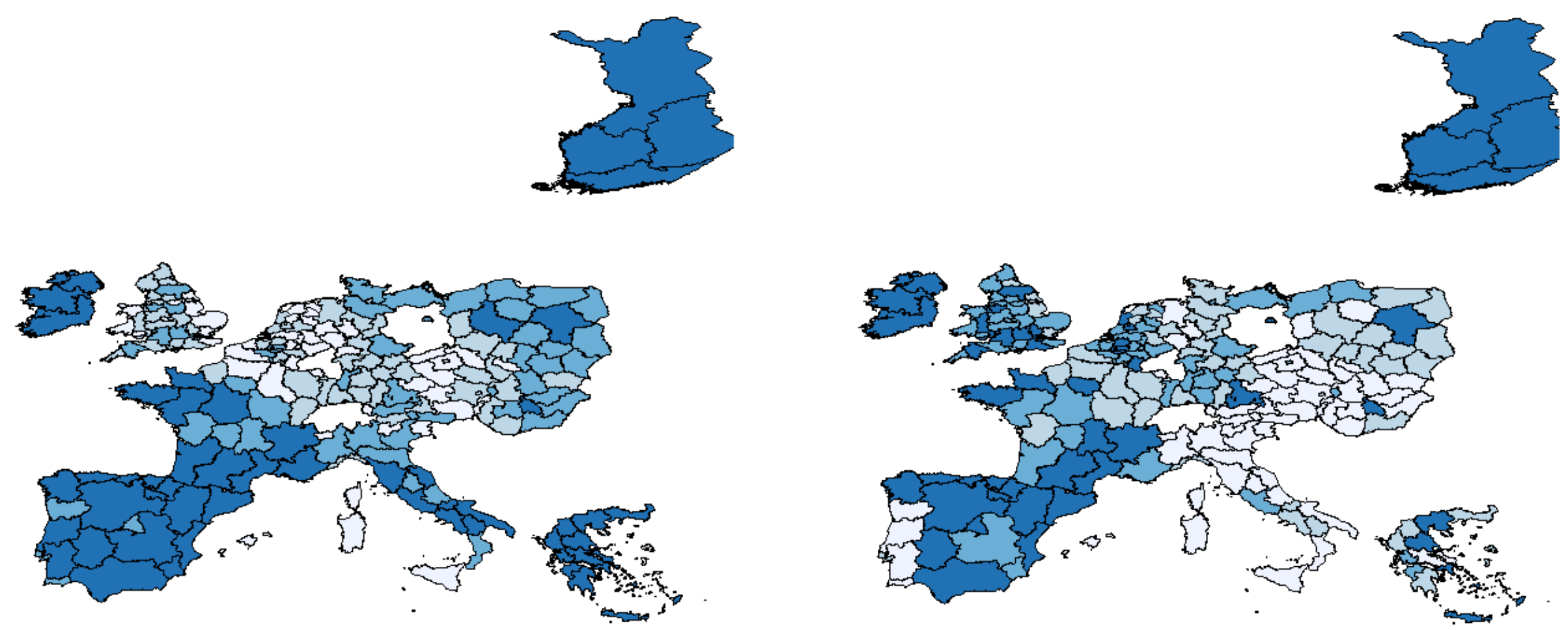

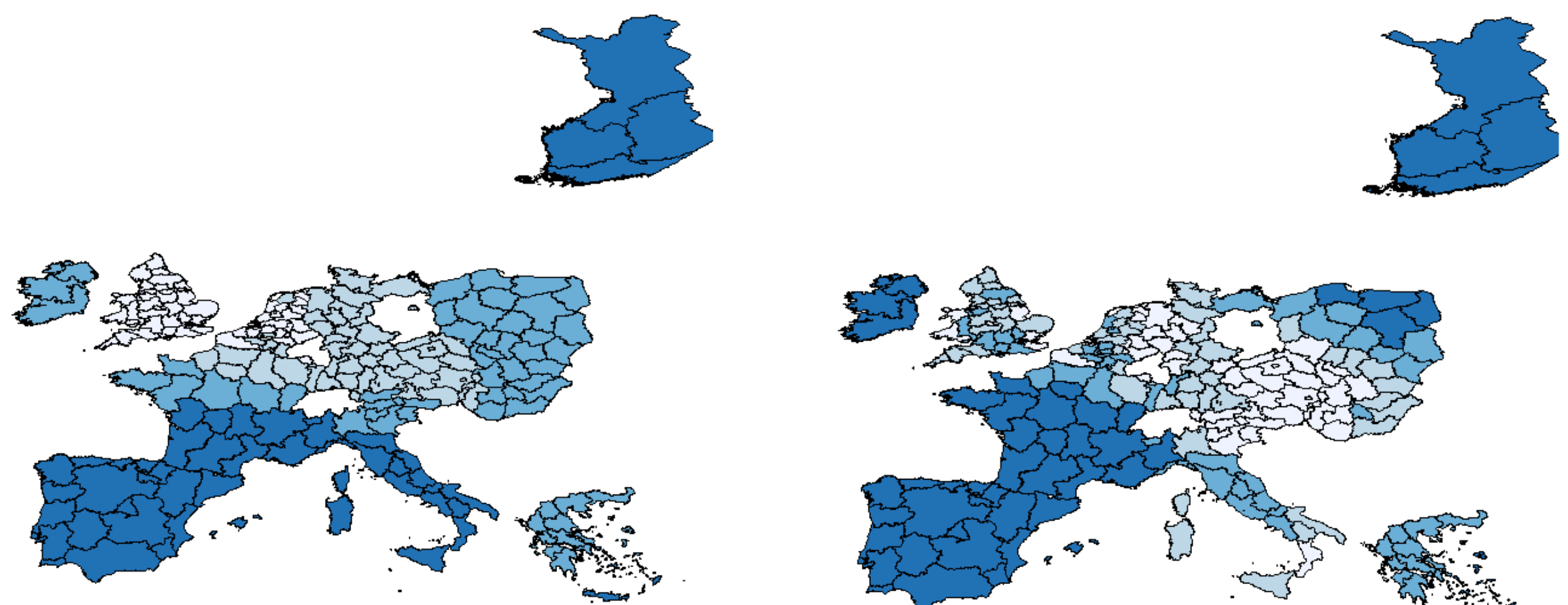

\section{Elasticity productivity - physical} capital (all regions) 1999

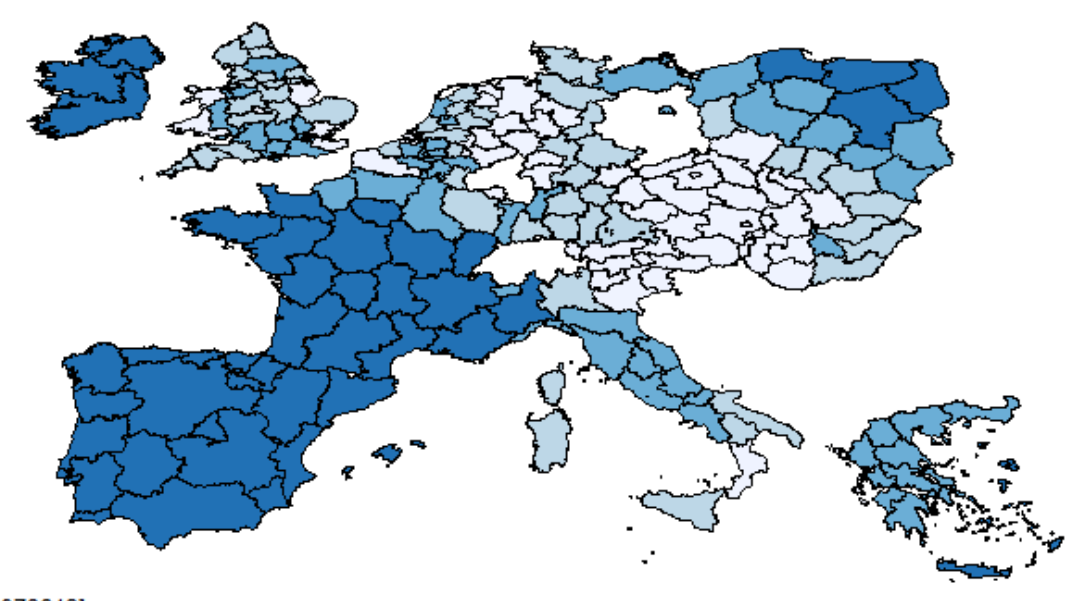

Elasticity productivity - physical capital (all regions) 2008 

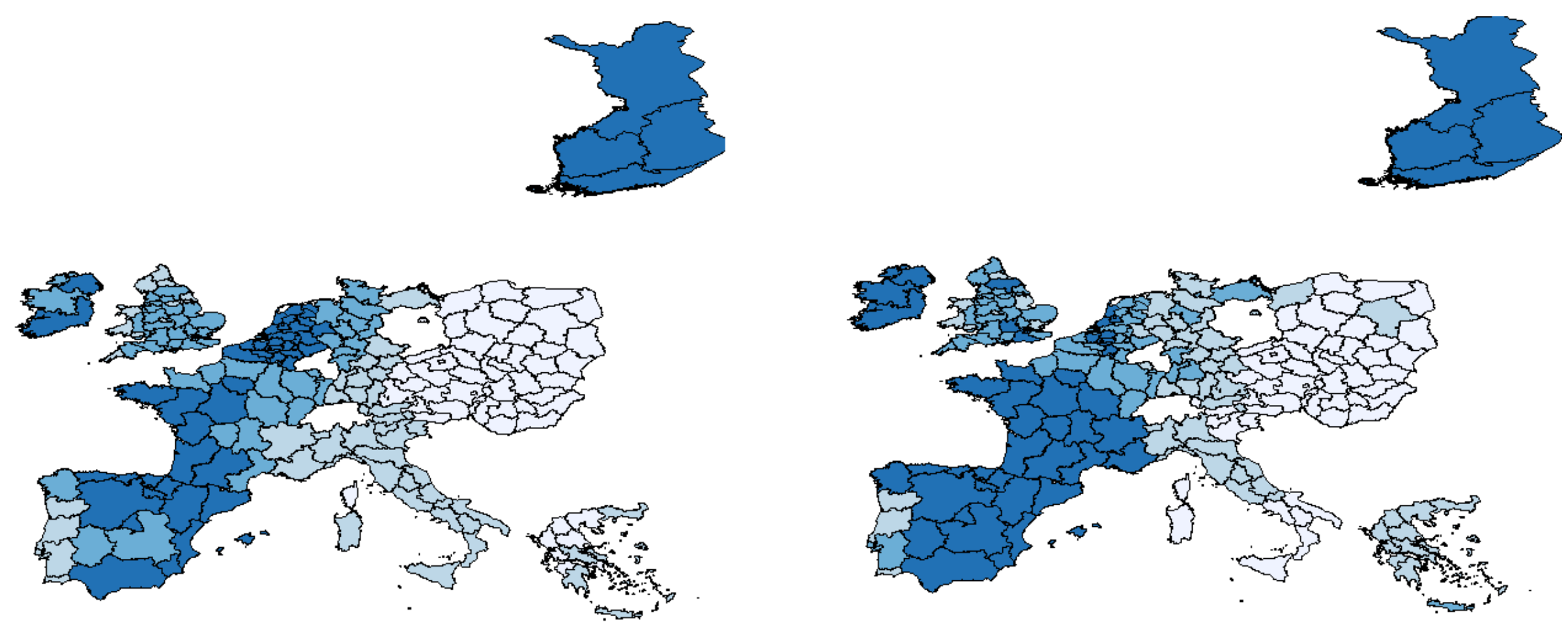
TABLE 1: Variables description

\begin{tabular}{|c|c|c|c|c|c|c|c|c|}
\hline & \multicolumn{4}{|c|}{1999} & \multicolumn{4}{|c|}{2008} \\
\hline & Mean & $\begin{array}{l}\text { Standard } \\
\text { Deviation }\end{array}$ & Maximum & Minimum & Mean & $\begin{array}{l}\text { Standard } \\
\text { Deviation }\end{array}$ & Maximum & Minimum \\
\hline $\begin{array}{c}\text { GVA per } \\
\text { worker } \\
(\log )\end{array}$ & 3.513 & 0.594 & $\begin{array}{c}4.249 \\
\text { (Inner } \\
\text { London) }\end{array}$ & $\begin{array}{c}1.887 \\
\text { (Podkarpackie) }\end{array}$ & 3.636 & 0.522 & $\begin{array}{c}4.504 \\
\text { (Inner } \\
\text { London) }\end{array}$ & $\begin{array}{c}2.202 \\
\text { (Lubelskie) }\end{array}$ \\
\hline $\begin{array}{l}\text { Physical } \\
\text { capital per } \\
\text { worker } \\
(\log )\end{array}$ & 4.819 & 0.490 & $\begin{array}{c}5.480 \\
\text { (Oberbayern) }\end{array}$ & $\begin{array}{c}3,206 \\
\text { (Podkarpackie) }\end{array}$ & 4.996 & 0.477 & $\begin{array}{c}5.743 \\
\text { (Flevoland) }\end{array}$ & $\begin{array}{c}3.434 \\
\text { (Lubelskie) }\end{array}$ \\
\hline $\begin{array}{l}\text { Human } \\
\text { Capital }\end{array}$ & 0.204 & 0.091 & $\begin{array}{c}0.460 \\
\text { (Inner } \\
\text { London) }\end{array}$ & $\begin{array}{c}0.021 \\
\text { (Bolzano) }\end{array}$ & 0.275 & 0.086 & $\begin{array}{c}0.564 \\
\text { (Inner } \\
\text { London) }\end{array}$ & $\begin{array}{c}0.084 \\
\text { (Severozápad) }\end{array}$ \\
\hline
\end{tabular}


TABLE 2: Spatial autocorrelation statistics

\begin{tabular}{ccccc}
\hline Year & Statistic & $\begin{array}{c}\text { GVA } \\
\text { per worker } \\
(\mathbf{l o g})\end{array}$ & $\begin{array}{c}\text { Capital } \\
\text { per worker } \\
(\mathbf{l o g})\end{array}$ & $\begin{array}{c}\text { Human } \\
\text { capital }\end{array}$ \\
\hline \multirow{2}{*}{$\mathbf{1 9 9 9}$} & Moran's I & $0.618^{* * *}$ & $0.523^{* * *}$ & $0.505^{* * *}$ \\
& Geary's C & $0.384^{* * *}$ & $0.451^{* * *}$ & $0.550^{* * *}$ \\
\multirow{2}{*}{$\mathbf{2 0 0 8}$} & & & & \\
& Moran's I & $0.600^{* * *}$ & $0.550^{* * *}$ & $0.499 * * *$ \\
& Geary's C & $0.387^{* * *}$ & $0.427^{* * *}$ & $0.580^{* * *}$ \\
\hline
\end{tabular}

Note: $* * *$ denotes significance at $1 \%$. 
TABLE 3: Maximum likelihood estimation results

\begin{tabular}{|c|c|c|c|c|}
\hline & 1999 & 2002 & 2005 & 2008 \\
\hline \multirow[t]{2}{*}{ Constant } & $-0.215^{*}$ & -0.217 & -0.193 & -0.186 \\
\hline & {$[0.125]$} & {$[0.136]$} & {$[0.124]$} & [0.117] \\
\hline \multirow[t]{2}{*}{$\varnothing$} & 0.032 & 0.017 & 0.007 & 0.000 \\
\hline & {$[0.040]$} & {$[0.040]$} & {$[0.041]$} & [0.039] \\
\hline \multirow[t]{2}{*}{$\lambda$} & 0.036 & $0.075 * * *$ & $0.081 * * *$ & $0.084 * * *$ \\
\hline & {$[0.027]$} & {$[0.027]$} & {$[0.025]$} & [0.024] \\
\hline \multirow[t]{2}{*}{$\alpha$} & $0.772 * * *$ & $0.782 * * *$ & $0.782 * * *$ & $0.783 * * *$ \\
\hline & [0.054] & {$[0.057]$} & [0.059] & {$[0.058]$} \\
\hline \multirow[t]{2}{*}{$\gamma$} & $0.918 * * *$ & $0.902 * * *$ & $0.888 * * *$ & $0.895 * * *$ \\
\hline & {$[0.056]$} & {$[0.074]$} & {$[0.080]$} & [0.092] \\
\hline \multirow[t]{2}{*}{$\delta$} & $0.753 * * *$ & $0.609 * * *$ & $0.622 * * *$ & $0.482 * *$ \\
\hline & {$[0.165]$} & {$[0.177]$} & {$[0.172]$} & {$[0.188]$} \\
\hline Log Lik & 137.32 & 134.76 & 145.38 & 149.64 \\
\hline Moran's I & 0.019 & 0.013 & 0.012 & 0.014 \\
\hline
\end{tabular}

Notes: Bootstrapped standard errors (999 replications) in brackets. Moran's I is computed over the residuals. $*$, **, and $* *$ denote significant at $10 \%, 5 \%$ and $1 \%$. 
TABLE 4: Average productivity elasticities in groups of EU regions

\begin{tabular}{cccccc}
\hline Elasticity & $\begin{array}{c}\text { Group of } \\
\text { Regions }\end{array}$ & $\mathbf{1 9 9 9}$ & $\mathbf{2 0 0 2}$ & $\mathbf{2 0 0 5}$ & $\mathbf{2 0 0 8}$ \\
\hline \multirow{3}{*}{$\xi_{\boldsymbol{k}}$ (local) } & Core & 0.825 & 0.827 & 0.819 & 0.814 \\
& South & 0.834 & 0.828 & 0.817 & 0.810 \\
& CEE & 0.823 & 0.819 & 0.810 & 0.805 \\
$\xi_{\boldsymbol{k}}$ (overall) & Core & 1.042 & 0.945 & 0.911 & 0.871 \\
& South & 1.123 & 0.987 & 0.929 & 0.887 \\
& CEE & 1.079 & 0.952 & 0.903 & 0.862 \\
& & & & & \\
$\xi_{\boldsymbol{h}}$ (local) & Core & 0.072 & 0.260 & 0.313 & 0.322 \\
& South & -0.020 & 0.173 & 0.229 & 0.292 \\
& CEE & -0.450 & -0.152 & -0.096 & 0.036 \\
\hline
\end{tabular}

Notes: Local refers to the percentage of productivity variation after a $1 \%$ increase in an average local region of the respective group. Overall refers to the percentage of productivity variation in an average region after a $1 \%$ increase in every region. 
FIGURE 1: Kernel density of GVA per worker (left) and physical capital per worker (right)
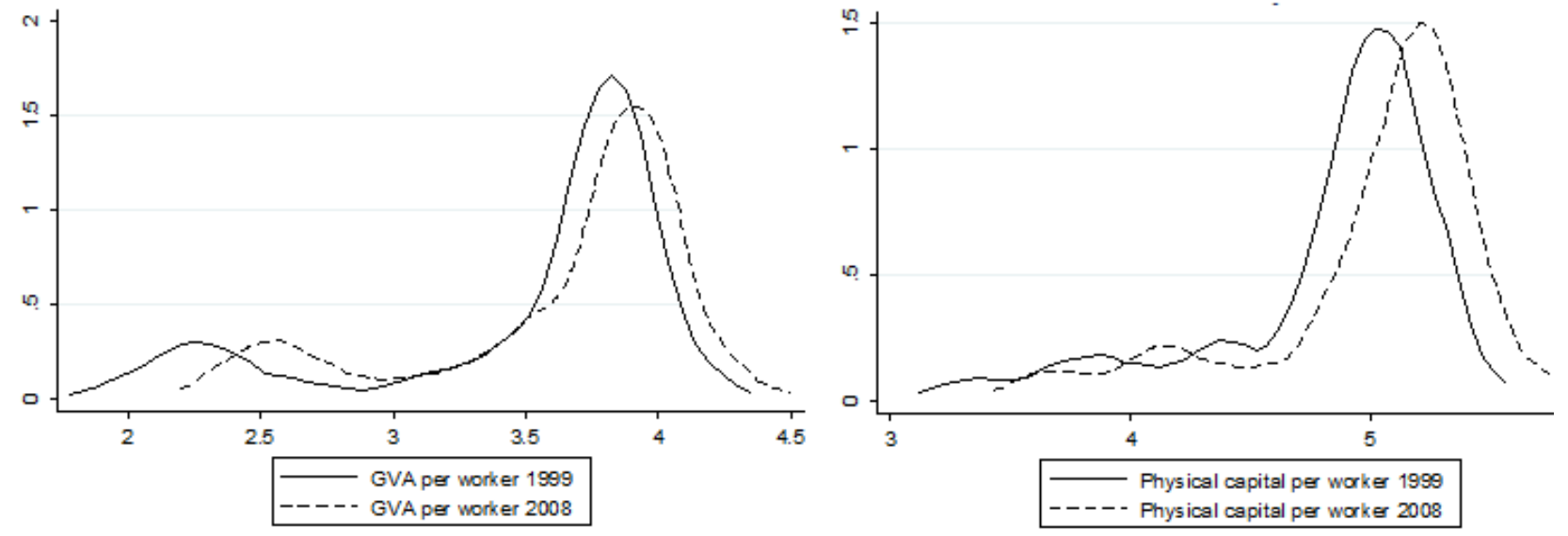

FIGURE 2: Kernel density of human capital

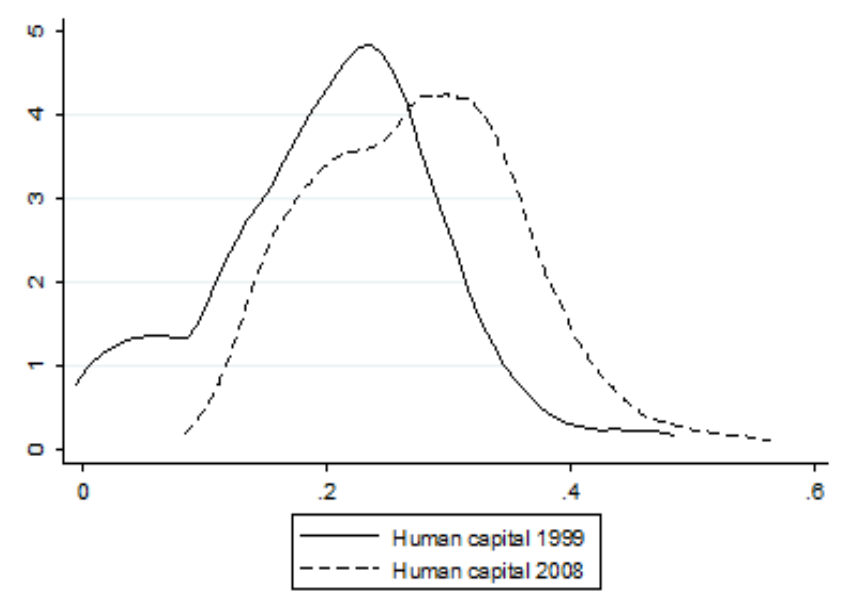


FIGURE 3: Kernel densities of local (left) and overall (right) elasticities of physical capital
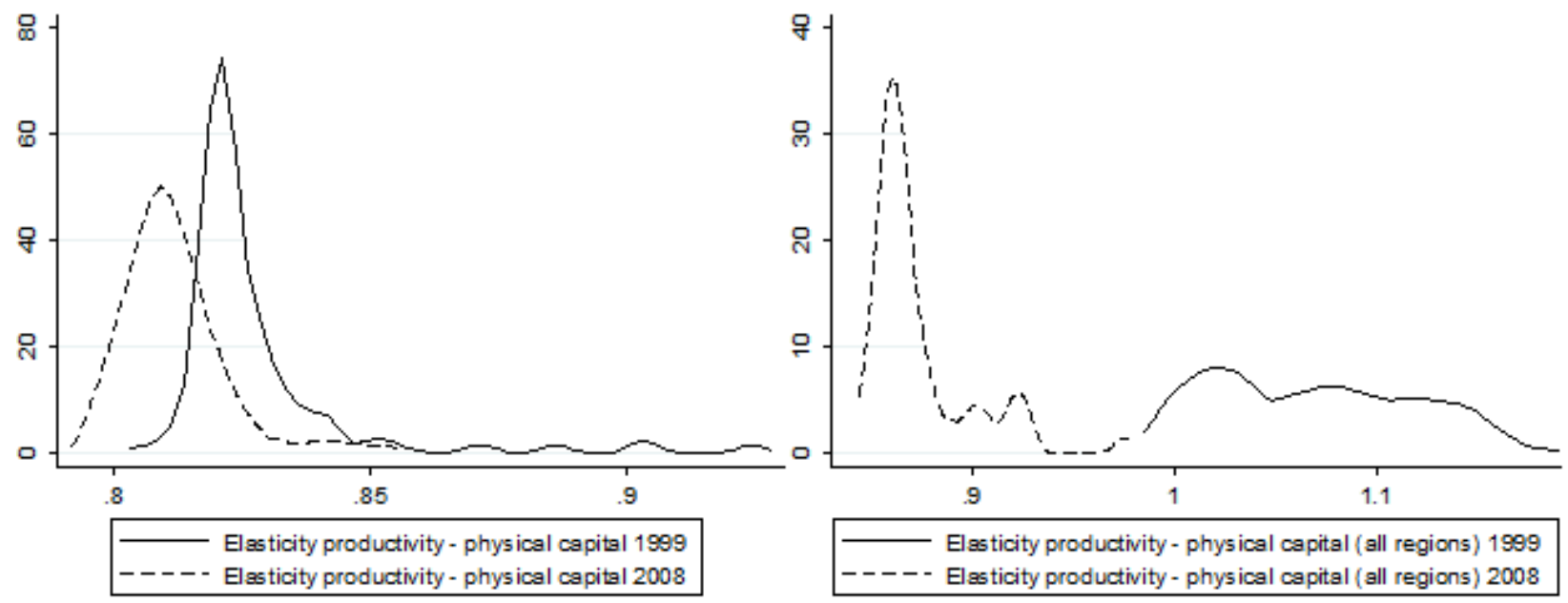

FIGURE 4: Kernel density of human capital elasticity

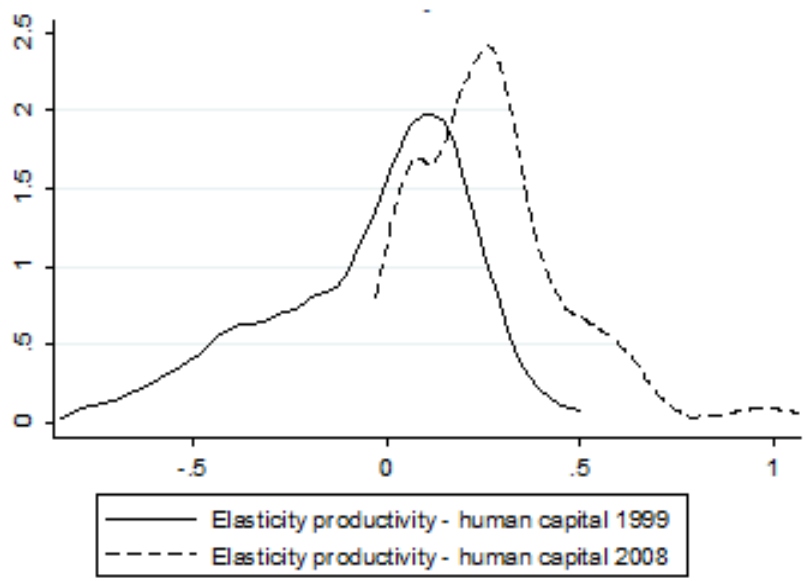


FIGURE 5: Capital contribution in 1999 (left) and 2008 (right) - averages by decile.

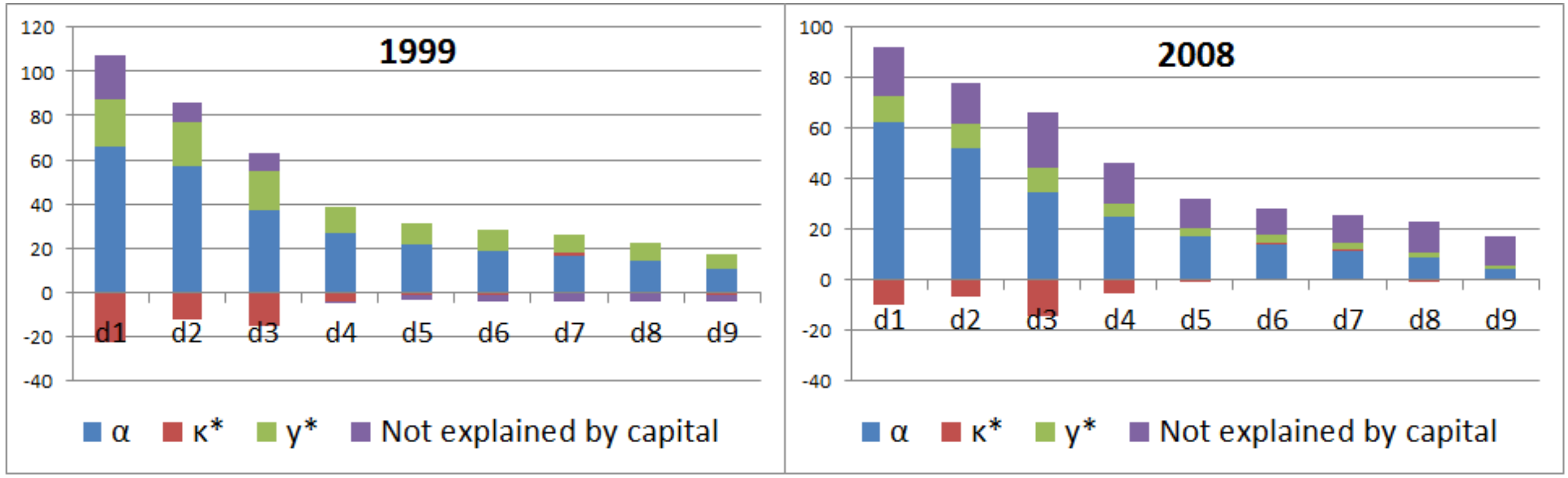


FIGURE 6: Capital contribution 1999 (left) and 2008 (right) - averages by groups of regions

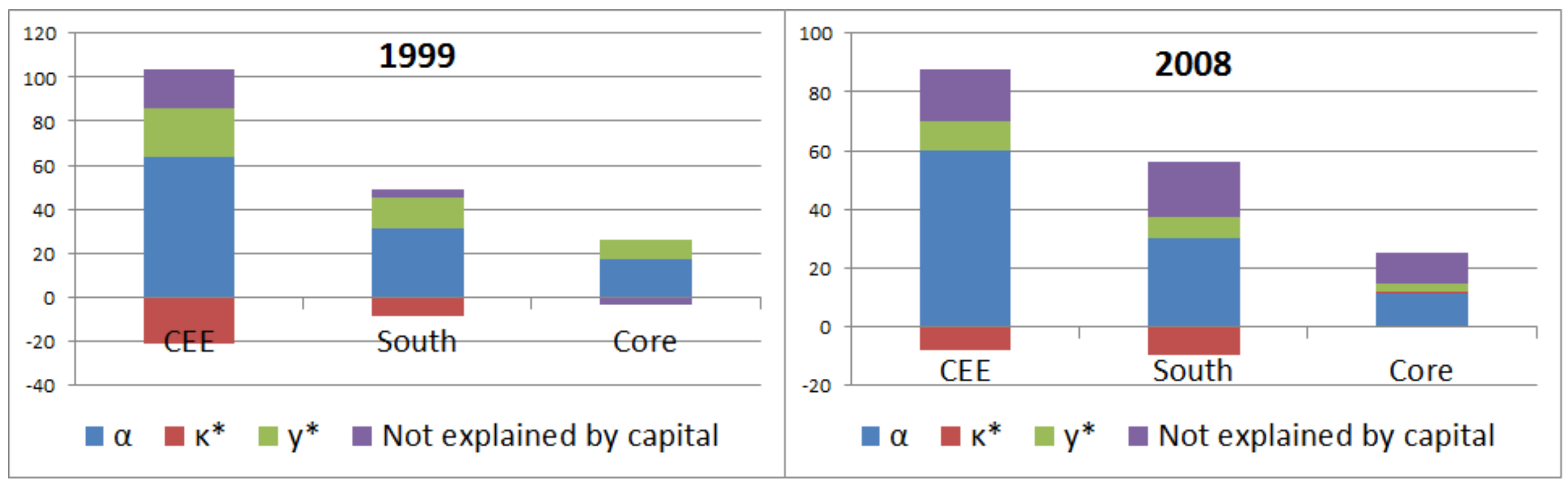

